\title{
ANALISIS SWOT PADA KANTOR JASA AKUNTAN YOHANES
}

\author{
Nataria \\ Program Studi Magister Manajemen Universitas Tarumanagara \\ natariacacaa@gmail.com \\ Haris Maupa \\ Program Studi Magister Manajemen Universitas Tarumanagara
}

Masuk : 03-12-2020, revisi : 20-12-2020, diterima untuk diterbitkan : 21-12-2020

\begin{abstract}
This research was conducted to find what marketing strategies are appropriate for the Yohanes Accounting Services Office in 2020. This research used data collection techniques by using interviews and observations. The data analysis technique uses the concept of Fred R. David's theory through 3 stages of strategic formulation, namely the input stage, matching stage, and decision stage. The input stage uses the Internal Factor Evaluation (IFE) Matrix and the External Factor Evaluation (EFE) Matrix. The next stage used the SWOT Matrix and Internal-External (IE) Matrix. In the final stage using the Quantitative Strategic Planning Matrix (QSPM). The results showed that the total value for IFE is 2.7081 while the total value for EFE is 3.0850. In the Internal-External (IE) matrix, it is known that Yohanes's Accounting Services Office is in a position of growth and development. Strategies that are suitable for this position are market penetration strategy, market development strategy, and product development strategy. At the decision stage, from the QSPM results, the main strategy alternative to be applied is the market development strategy with a total value of attractiveness (TAS) of 6.7568. This strategy seeks to increase the market share of a product through efforts to make improvements, enhancements, and developments.
\end{abstract}

Keywords: Strategy, IFE, EFE, SWOT, QSPM, Accounting Services Office

\begin{abstract}
Abstrak: Penelitian ini dilakukan dengan tujuan untuk mengetahui strategi pemasaran apa yang sesuai diterapkan bagi Kantor Jasa Akuntan Yohanes pada tahun 2020. Pada tahap akhir menggunakan Quantitative Strategic Planning Matrix (QSPM). Berdasarkan hasil dari matriks IFE dan EFE yang dikumpulkan, dapat diketahui total nilai untuk IFE adalah sebesar 2,7081 sedangkan total nilai untuk EFE adalah sebesar 3,0850. Pada matching stage pada matrik SWOT didapatkan beberapa kemungkinan alternatif strategi dengan cara menggunakan kekuatan yang dimiliki untuk memanfaatkan peluang, memanfaatkan peluang untuk mengatasi kelemahan, menggunakan kekuatan yang dimiliki untuk menghindari ancaman dan meminimalisasikan kelemahan dan menghindari ancaman. Pada matrik Internal-Eksternal (IE) diketahui bahwa Kantor Jasa Akuntan Yohanes berada pada posisi tumbuh dan bina, strategi yang cocok pada posisi ini adalah strategi penetrasi penetrasi pasar, startegi pengembangan pasar dan strategi pengembangan produk. Pada decision stage dari hasil QSPM dapat diperoleh alternatif strategi utama yang diterapkan yaitu strategi pengembangan pasar dengan Total Nilai Daya Tarik (TAS) sebesar 6,7568. Strategi ini berusaha untuk meningkatkan pangsa pasar suatu produk melalui usaha melakukan perbaikan, peningkatan dan pengembangan.
\end{abstract}

Kata kunci: Strategi, IFE, EFE, SWOT, QSPM, Kantor Jasa Akuntan.

\section{PENDAHULUAN}

Pusat Pembinaan Profesi Keuangan Kementerian Keuangan melalui Peraturan Menteri Keuangan Republik Indonesia Nomor 25 / PMK.01 / 2014 mengizinkan akuntan beregister mendirikan Kantor Jasa Akuntan (KJA) jika telah memenuhi persyaratan yang ditentukan. Dengan adanya peraturan tersebut, maka akan membuka peluang besar bagi tenaga profesional 
yang ingin mendirikan KJA baru. Dengan demikian, persaingan dalam industri KJA akan semakin ketat. Maupa (2019) menyatakan bahwa KJA memiliki ukuran keberhasilannya dalam menghadapi persaingan yaitu dengan menggunakan tingkat penjualan, sehingga industri KJA menghasilkan prospek yang lebih baik ke depannya dalam menghadapi persaingan di pasar.

Motivasi peneliti yang menjadi dasar dalam melakukan penelitian ini adalah mengidentifikasi faktor internal dan eksternal yang mempengaruhi keunggulan sebuah bisnis KJA serta strategi yang tepat untuk perusahaan agar dapat memenangkan persaingan bisnisnya. Dalam perencanaan strategi, diperlukan sebuah analisis yang pada umumnya dikenal sebagai Strength, Weakness, Opportunities, dan Threat (SWOT) (David 2004). Dalam analisis ini, poin $\mathrm{S}$ dan $\mathrm{W}$ adalah faktor internal KJA Yohanes, sedangkan poin $\mathrm{O}$ dan $\mathrm{T}$ adalah faktor eksternal KJA Yohanes. Kemudian, akan terbentuk sebuah rangkaian atau rancangan strategi yang bisa diukur dan dikontrol secara keseluruhan sehingga KJA Yohanes tetap dapat menjalankan usahanya dengan baik dan lebih menguntungkan.

\section{Tujuan Penelitian}

Tujuan penelitian ini adalah merencanakan strategi KJA Yohanes dengan melakukan identifikasi faktor internal dan eksternal KJA dalam rangka meningkatkan proses bisnis yang ada di KJA Yohanes dengan menggunakan Matriks Internal Factor Evaluation (IFE Matrix), Matriks External Factor Evaluation (EFE Matrix), Analisis Matriks SWOT, Analisis Matriks IE (Internal-External), dan Analisis Quantitative Strategic Planning Matrix (QSPM).

\section{TELAAH KEPUSTAKAAN}

Freddy (2002) mengungkapkan bahwa strategi adalah sebuah tindakan yang memiliki sifat incremental (senantiasa meningkat) serta terus menerus terjadi yang didasarkan pada sudut pandang atas harapan para pelanggan di masa depan. Sehingga, perencanaan strategi pada umumnya tidak dimulai dengan "apa yang terjadi", namun dimulai dengan "apa yang akan terjadi". Kompetensi inti dalam bisnis yang dilakukan sangat diperlukan untuk menghasilkan terjadinya kecepatan inovasi pasar baru serta perubahan pola konsumen.

David (2009) berpendapat dalam bukunya "Manajemen Strategi", konsep matriks SWOT adalah sebuah perangkat mencocokan yang sangat penting dalam membantu manajer untuk mengembangkan 4 tipe strategi SO WO dan ST WT. Strategi SO merupakan strategi kekuatan-peluang yang memanfaatkan peluang eksternal perusahaan dengan menggunakan kekuatan internalnya. Dalam sebuah perusahaan yang memiliki kelemahan cukup besar, perusahaan harus melakukan sebuah usaha dalam mengatasi kelemahan tersebut dan kemudian mengubahnya menjadi kekuatan. Sebuah organisasi dalam menghadapi ancaman yang besar, pada umumnya akan berusaha untuk menghindarinya dan memusatkan perhatiannya pada peluang yang dimiliki.

David (2011) berpendapat bahwa Matriks QSPM merupakan sebuah alat untuk menganalisis yang memberikan kemungkinan untuk penyusun strategi dalam melakukan evaluasi berbagai strategi alternatif secara objektif, tentunya didasarkan pada faktor keberhasilan internal dan ekternal yang sudah dilakukan identifikasi sebelumnya. Pada kolom kiri matriks QSPM, memuat berbagai faktor internal dan eksternal yang telah diperoleh melalui matriks IFE dan EFE, pada baris paling atas memuat berbagai strategi alternatif yang telah diperoleh melalui matriks TWOS, IE, dan QSPM.

Kantor Jasa Akuntan merupakan bentuk badan usaha yang terdiri dari berbagai jenis, seperti: perseorangan, firma, persekutuan perdata, atau perseroan terbatas. KJA dengan bentuk badan usaha perseorangan, dalam pendiriannya wajib untuk dilakukan serta dikelola oleh 1 (satu) orang Akuntan Berpraktik. KJA dengan bentuk badan usaha persekutuan perdata dan firma, dalam pendiriannya wajib untuk dilakukan serta dikelola oleh paling sedikit 2 (dua) orang Rekan yang telah memenuhi paling sedikit 1/2 (satu per dua) dari seluruh Rekan yang merupakan Akuntan Berpraktik. (Kementerian Keuangan, 2017) 


\section{METODOLOGI PENELITIAN}

Metode penelitian yang digunakan dalam penelitian ini adalah metode deskriptif yang merupakan penelitian terhadap masalah-masalah berupa fakta saat ini dari suatu penelitian. Lokasi penelitian adalah di Kantor Jasa Akuntan Yohanes. Responden dalam penelitian ini adalah partner, senior akuntan dan manajer akuntan sebanyak 4 orang. Penelitian dilakukan dengan melakukan pengumpulan data melalui pengamatan langsung atau observasi, wawancara, survey, dan dokumentasi.

\section{Metode Analisis}

1. Melakukan analisa terhadap visi, misi, tujuan dan strategi perusahaan.

2. Melakukan analisa matriks IFE dan EFE

3. Melakukan analisa matriks SWOT

4. Melakukan analisa matriks IE

5. Melakukan analisa matriks QSPM

\section{ANALISA \& PEMBAHASAN}

Kantor Jasa Akuntan (KJA) Yohanes telah mendapatkan izin dari Kementrian Keuangan Republik Indonesia No.499/KM.1PPPK/2018 tanggal 6 Juni 2018 dan tergabung dalam Ikatan Akuntan Indonesia (IAI).

\section{Analisis Visi dan Misi Perusahaan}

Visi KJA Yohanes adalah: "Become an international accountancy services office in 2028". Misi KJA Yohanes adalah: "Provide accountancy services with quality maintained in accordance with professional standards; Have competent human resources, integrity and adhere to the professional code of ethics; and Establish and expand cooperation with various parties, both domestic and abroad".

Analisis Matriks Internal Factor Evaluation (IFE) \& External Factor Evaluation (EFE)

Tabel 1

Analisis Matriks IFE EFE

\begin{tabular}{|c|c|c|c|c|c|c|c|c|c|c|c|}
\hline \multirow[b]{2}{*}{ Faktor-faktor Strategi Eksternal } & \multicolumn{5}{|c|}{ Bobot } & \multicolumn{5}{|c|}{ Rating } & \multirow[b]{2}{*}{ Nilai } \\
\hline & Ml & $\mathrm{M}_{2}$ & M3 & M4 & $\begin{array}{l}\text { Rata- } \\
\text { Rata }\end{array}$ & $\mathrm{Ml}$ & M. & $\mathrm{M} 3$ & M4 & $\begin{array}{l}\text { Rata- } \\
\text { Rata }\end{array}$ & \\
\hline Peluang (0) & & & & & & & & & & & \\
\hline 1. Kurangnya jumlah akuntan yang telah mendapatkan izin dan teregistrasi dalam Kementerian Kevangan. & 0.1 & 0.10 & $0.10 \mid$ & 0.08 & 0.11 & 4 & 4 & 3 & 3 & 4 & 0.37 \\
\hline 2. Pertumbuhan ekonomi Indonesia semakin bertumbuh yang menyebabkan semua industri membutuhkan akuntansi keuangan. & 0.10 & 0.08 & 0.12 & 0.09 & 0.10 & 4 & 3 & 4 & 3 & 4 & 0.34 \\
\hline $\begin{array}{l}\text { 3. UMR yang setiap tahvon meningkat sehingga mengakibatkan gaji yang dibayarkan pervahahan semakin tinggi untuk merekrut staff } \\
\text { Akuntansi. }\end{array}$ & 0.06 & 0.08 & 0.05 & 0.04 & 0.06 & 3 & 4 & 2 & 2 & 3 & 0.16 \\
\hline $\begin{array}{l}\text { 4. Pemerintah mendorong pervashaan private menjadi pervaahaan terbuka dengan mengeluarkan peraturan untuk mempermudah } \\
\text { proses Go Public. }\end{array}$ & 0.05 & 0.04 & 0.09 & 0.10 & 0.07 & 3 & 3 & 3 & 2 & 3 & 0.19 \\
\hline 5. Semakin banyaknya bisnis start up yang belum memiliki pengetahuan tentang akuntansi kevangan. & 0.05 & 0.08 & 0.05 & 0.10 & 0.07 & 3 & 3 & 3 & 2 & 3 & 0.19 \\
\hline $\begin{array}{l}\text { 6. Kebutuhan Laporan Kevangan berkualitas yang disyaratkan oleh OKK dan Bank Indonesia saat pervsahaan mengajukan kredit. } \\
\text { Ancaman (T) }\end{array}$ & 0.12 & 0.04 & 0.06 & 0.05 & 0.07 & 4 & 4 & 3 & 3 & 4 & 0.24 \\
\hline 1. Banyak Kompetitor dari Kantor Jasa Akuntan lain yang memiliki "nama" yang sudah besar. & 0.10 & 0.08 & 0.10 & 0.10 & 0.10 & 4 & 4 & 4 & 3 & 4 & 0.36 \\
\hline 2. Peraturan ketetapan yang dikeluarkan oleh pemerintah dalam ruang lingkup perijinan Kantor Jasa Akuntan selalu bervbah. & 0.08 & 0.03 & 0.05 & 0.06 & 0.06 & 4 & 2 & 1 & 2 & 2 & 0.12 \\
\hline 3. Pengawasan OJK yang semakin ketat dalam mereview laporan keuangan yang disajikan oleh pervsahaan-pervsahaan. & 0.07 & 0.05 & 0.08 & 0.09 & 0.07 & 4 & 4 & 2 & 2 & 3 & 0.22 \\
\hline $\begin{array}{l}\text { 4. Belum adanya kesiapan Akuntan dalam Perkembangan Teknologi yang semakin berkembang ditandai dengan kurangnya } \\
\text { penguasaan software akuntansi barv. }\end{array}$ & 0.05 & 0.12 & 0.11 & 0.10 & 0.10 & 3 & 3 & 4 & 2 & 3 & 0.29 \\
\hline 5. Belum adanya kesiapan akuntan dalam menghadapi era pasar global (MEA) yang ditandai dengan kurangnya penguasaan bahasa & 0.08 & 0.12 & 0.04 & 0.07 & 0.08 & 3 & 4 & 3 & 3 & 3 & 0.25 \\
\hline $\begin{array}{l}\text { 6. Lulvsan pergurvan tinggi program stvdi akuntansi yang semakin banyak sehingga persaingan untuk membuka usaha jasa akuntan } \\
\text { semakin tinggi. }\end{array}$ & 0.07 & 0.13 & 0.05 & 0.05 & 0.08 & 3 & 3 & 3 & 2 & 3 & 0.21 \\
\hline 7. Terjadinya krisis global diseluruh dunnia yang berdampak meningkatkan resiko terhadap laporan keuangan. & 0.03 & 0.05 & 0.10 & 0.07 & 0.06 & 3 & 2 & 2 & 3 & 3 & 0.16 \\
\hline Total & 1.00 & 1.00 & 1.00 & 1.00 & & & & & & & 3.09 \\
\hline
\end{tabular}




\begin{tabular}{|c|c|c|c|c|c|c|c|c|c|c|c|}
\hline \multirow[b]{2}{*}{ Faktor-faktor Strategi Internal } & \multicolumn{5}{|c|}{ Bobot } & \multicolumn{5}{|c|}{ Rating } & \multirow[b]{2}{*}{ Nilai } \\
\hline & Ml & $\mathrm{M} 2$ & $\mathrm{M} 3$ & M4 & \begin{tabular}{|l|l} 
Rata- \\
Rata
\end{tabular} & $\mathrm{Ml}$ & M2 & $\mathrm{M} 3 \mathrm{P}$ & $\mathrm{M} 4$ & $\begin{array}{l}\text { Rata- } \\
\text { Rata } \\
\end{array}$ & \\
\hline Kekuatan (S) & & & & & & & & & & & \\
\hline 1. Kantor Jasa Akuntan svdah memiliki izin resmi dan teregister oleh Kementerian Keuangan. & 0.08 & 0.08 & 0.11 & 0.06 & 0.08 & 3 & 4 & 4 & 2 & 3 & 0.27 \\
\hline 2. KJA Yohanes memilik lokasi strategis yang berada di lingkungan industri. & 0.08 & 0.10 & 0.06 & 0.07 & 0.08 & 4 & 3 & 2 & 2 & 3 & 0.21 \\
\hline 3. KJA Yohanes memiliki proses client acceptance sebelum melakukan engagement sehingga meminimalkan resiko jasa akuntan. & 0.03 & 0.05 & 0.04 & 0.06 & 0.05 & 3 & 3 & 2 & 2 & 3 & 0.11 \\
\hline 4. KJA Yohanes memiliki staff yang mempunyai berbagai pengalaman dibidang berbagai incustri. & 0.05 & 0.10 & 0.07 & 0.05 & 0.07 & 3 & 3 & 1 & 1 & 2 & 0.14 \\
\hline 5. Kantor Jasa Akuntan Yohanes svdah menerapkan sistem pengendalian mutv yang diterapkan oleh Kementerian Kevangan. & 0.08 & 0.09 & 0.07 & 0.09 & 0.08 & 4 & 4 & 2 & 2 & 3 & 0.25 \\
\hline 6. Staff Kantor Jasa Akuntan svdah memiliki sertifikasi keahlian dibidang akuntansi. & 0.04 & 0.09 & 0.12 & 0.13 & 0.10 & 2 & 2 & 3 & 4 & 3 & 0.26 \\
\hline $\begin{array}{l}\text { 7. Kantor Jasa Akuntan memiliki data base keuangan yang lengkap karena bekerjasama dengan BI, Kementerian Kevangan, OJK. } \\
\text { Kelemahan (W) }\end{array}$ & 0.04 & 0.12 & 0.06 & 0.11 & 0.08 & 2 & 4 & 2 & 4 & 3 & 0.25 \\
\hline 1. KJA Yohanes baru memulai operasional pada tahun 2018. & 0.10 & 0.06 & 0.08 & 0.05 & 0.07 & 4 & 3 & 2 & 2 & 3 & 0.20 \\
\hline 2. Sedikitnya kegiatan pemasaran, hanya sistem mouth to mouth berdasarkan pengalaman klien menggunakan kantor jasa akuntan. & 0.11 & 0.07 & 0.05 & 0.04 & 0.07 & 3 & 3 & 3 & 1 & 3 & 0.17 \\
\hline 3. Jumlah karyawan untuk level supervisor terbatas sehingga menghambat proses review laporan klien. & 0.12 & 0.08 & 0.10 & 0.10 & 0.10 & 1 & 3 & 3 & 3 & 3 & 0.25 \\
\hline 4. KJA Yohanes masih menggunakan sistem manual dalam melakukan engagement klien. & 0.03 & 0.03 & 0.08 & 0.05 & 0.05 & 4 & 3 & 3 & 1 & 3 & 0.13 \\
\hline 5. Kendaraan operasional yang terbatas pada saat mengadakan meeting dengan klien. & 0.18 & 0.03 & 0.08 & 0.06 & 0.09 & 4 & 1 & 3 & 1 & 2 & 0.20 \\
\hline 6. KJA Yohanes hanya memiliki ijin dibidang non assurance tetapi belum memiliki ijin dibidang assurance. & 0.06 & 0.10 & 0.08 & 0.13 & 0.09 & 3 & 4 & 2 & 3 & 3 & 0.28 \\
\hline Total & 1.00 & 1.00 & 1.00 & 1.00 & & & & & & & 2.71 \\
\hline
\end{tabular}

Dari perhitungan pembobotan rata-rata tertimbang yang dilakukan terhadap faktor internal perusahaan, didapatkan bahwa matriks IFE menghasilkan skor tertimbang sebesar 2,71 dan matriks EFE menghasilkan skor tertimbang 3,09.

\section{Matriks SWOT}

Tabel 2

\section{Analisis Matriks SWOT}

\begin{tabular}{|c|c|}
\hline Kekuatan (S) & Kelemahan (W) \\
\hline $\begin{array}{l}\text { 1. Kantor Jasa Akuntan svdah memiliki izin resmi dan teregister oleh Kementerian Kevangan. } \\
\text { 2. KJA Yohanes memilik lokasi strategis yang berada di lingkungan industri. } \\
\text { 3. KJA Yohanes memiliki proses client acceptance sebelum melakukan engagement sehingga meminimalkan } \\
\text { resiko jasa akuntan. } \\
\text { 4. KJA Yohanes memiliki staff yang mempunyai berbagai pengalaman dibidang berbagai industri. } \\
\text { 5. Kantor Jasa Akuntan Yohanes sudah menerapkan sistem pengendalian mutu yang diterapkan oleh } \\
\text { Kementerian Kevangan. } \\
\text { 6. Staff Kantor Jasa Akuntan svdah memiliki sertifikasi keahlian dibidang akuntansi. } \\
\text { 7. Kantor Jasa Akuntan memiliki data base kevangan yang lengkap karena bekerjasama dengan BI, Kementerian } \\
\text { Kevangan, OJK. }\end{array}$ & $\begin{array}{l}\text { 1. KJA Yohanes baru memulai operasional pada tahun } 2018 \text {. } \\
\text { 2. Sedikitnya kegiatan pemasaran, hanya sistem mouth tp mouth berdasarkan pengalaman klien menggunakan } \\
\text { kantor jasa akuntan. } \\
\text { 3. Jumlah karyawan untuk level supervisor terbatas sehingga menghambat proses review laporan klien. } \\
\text { 4. KJA Yohanes masih menggunakan sistem manual dalam melakukan engagement klien. } \\
\text { 5. Kendaraan operasional yang terbatas pada saat mengadakan meeting dengan klien. } \\
\text { 6. KJA Yohanes hanya memiliki ijin dibidang non assurance tetapi belum memiliki ijin dibidang assurance. }\end{array}$ \\
\hline $\begin{array}{l}\text { Peluang ( }(\mathrm{)}) \\
\text { 1. Kurangnya jumlah akuntan yang telah mendapatkan izin dan teregistrasi dalam Kementerian Kevangan. } \\
\text { 2. Pertumbuhan ekonomi Indonesia semakin bertumbuh yang menyebabkan semua industri membutuhkan } \\
\text { akuntansi kevangan. } \\
\text { 3. UMR yang setiap tahun meningkat sehingga mengakibatkan gaji yang dibayarkan pervsahaan semakin tinggi } \\
\text { untuk merekrut staff Akuntansi. } \\
\text { 4. Pemerintah mendorong pervsahaan private menjadi pervsahaan terbuka dengan mengeluarkan peraturan } \\
\text { untuk mempermudah proses Go Public. } \\
\text { 5. Semakkin banyaknya bisnis start up yang belum memiliki pengetahuan tentang akuntansi kevangan. } \\
\text { 6. Kebutuhan Laporan Kevangan berkualitas yang disyaratkan oleh OJK dan Bank Indonesia saat pervuahaan } \\
\text { mengajukan kredit. }\end{array}$ & 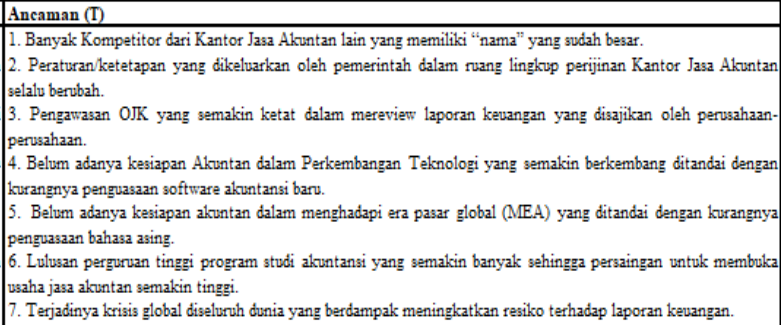 \\
\hline
\end{tabular}

\section{Matriks IE}

Matriks IE digunakan untuk merumuskan strategi yang telah digunakan yaitu matriks internal dan eksternal. Matrik ini didasarkan oleh dua dimensi kunci yaitu IFE pada sumbu X dan EFE pada sumbu Y. Kantor Jasa Akuntan Yohanes memiliki total nilai 2,7081 pada faktor internal dan total nilai 3,0850 pada factor ekternal. Kantor Jasa Akuntan Yohanes berada pada posisi sel IV, yang menggunakan strategi penetrasi pasar, pengembangan pasar, dan pengembangan produk. 
Matriks QSPM

Tabel 3

Analisis Matriks QSPM

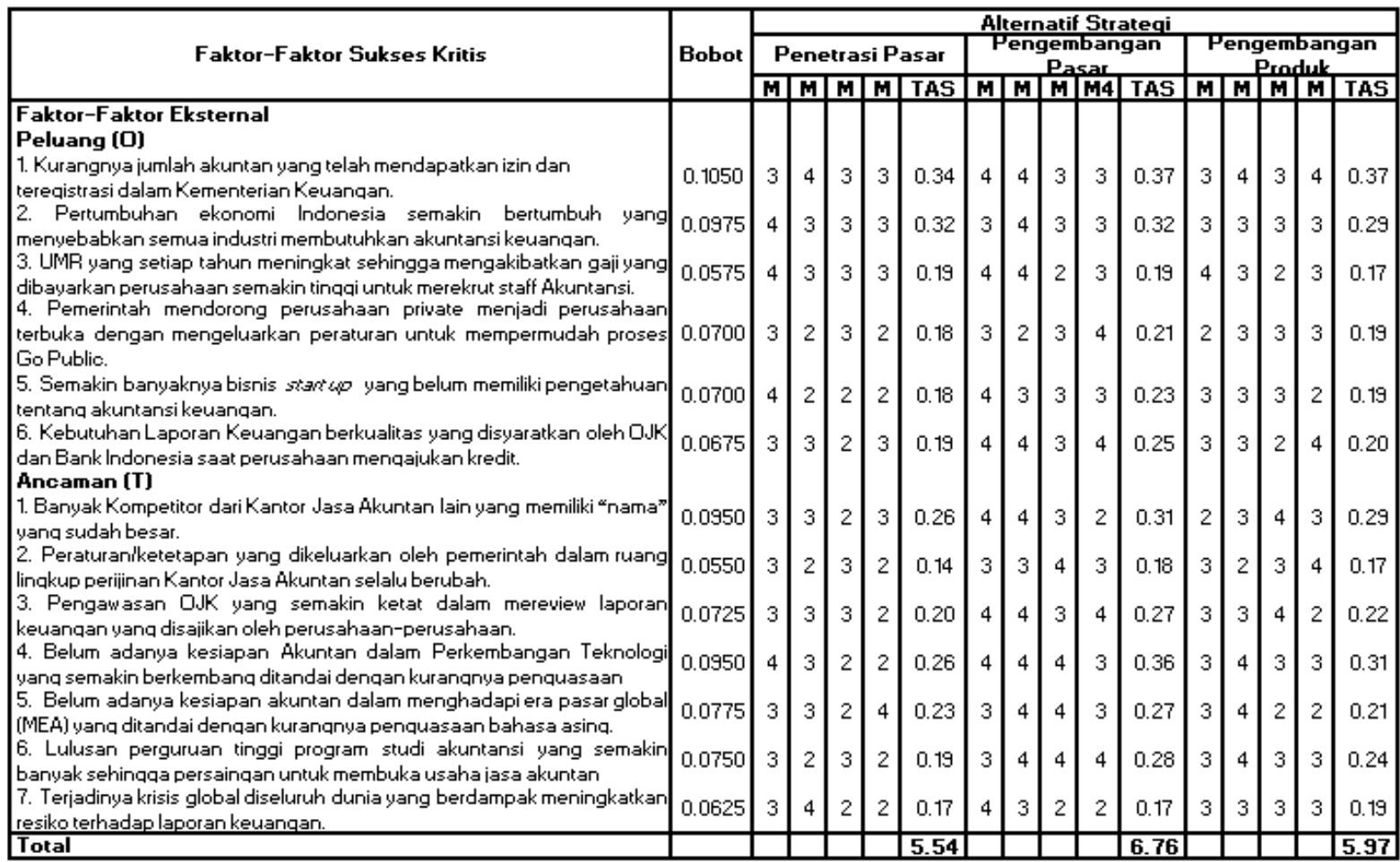

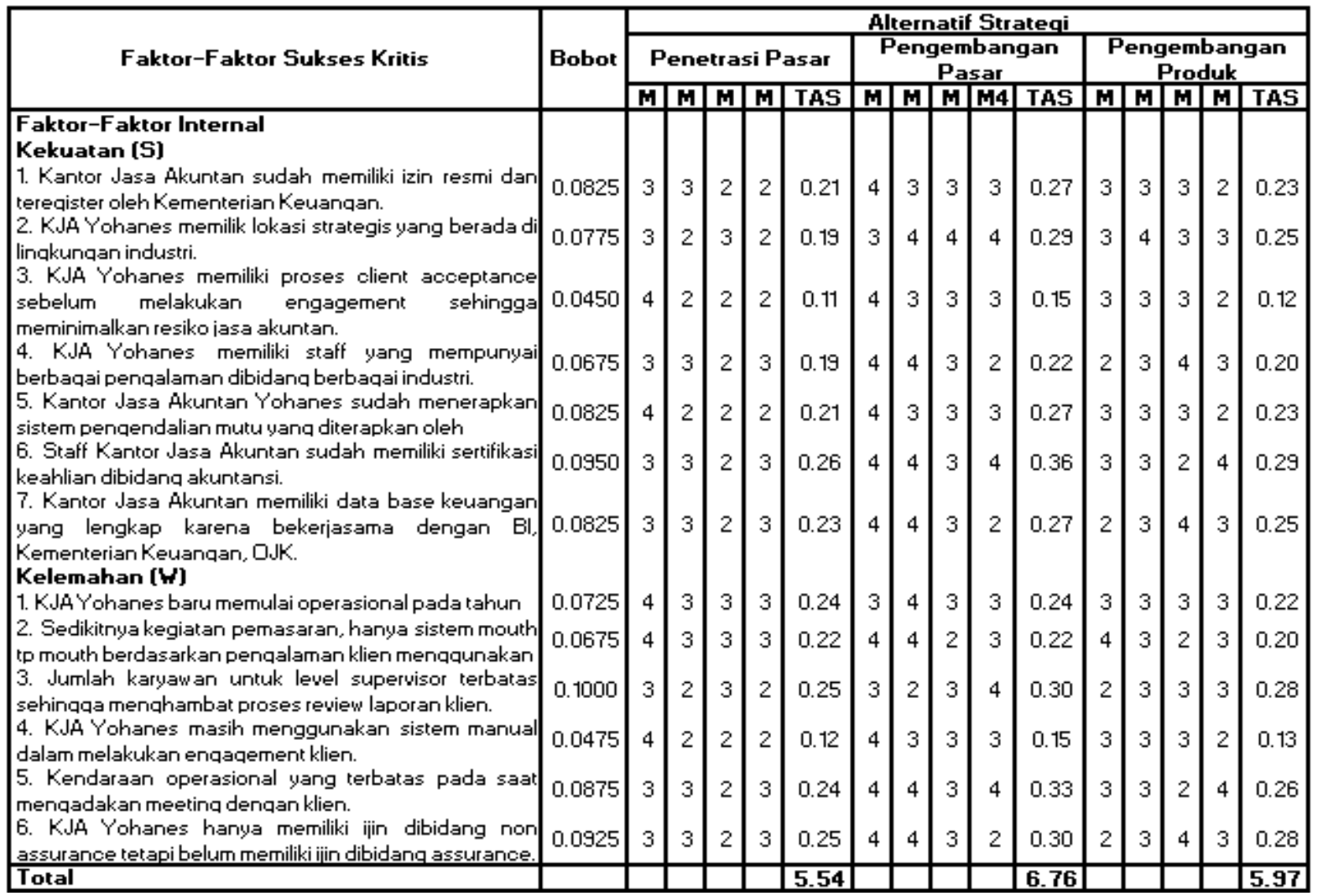

\section{KESIMPULAN DAN SARAN}

Kesimpulan studi ini sebagai berikut:

Pertama, Kantor Jasa Akuntan (KJA) adalah badan usaha yang memberikan Jasa Akuntansi. Jasa tersebut antara lain ; Jasa Pembukuan, Jasa Kompilasi Laporan Keuangan, Jasa Manajemen, Akuntansi Manajemen, Konsultasi Manajemen, Jasa Perpajakan, Jasa Prosedur 
yang Disepakati atas Informasi Keuangan, dan Jasa Sistem Teknologi Informasi. Kantor Jasa Akuntansi (KJA) dilarang memberikan Jasa Assurance.

Kedua, salah satu strategi yang paling efektif dan populer adalah Pengembangan Pasar Kantor Jasa Akuntan Yohanes haruslah melakukan pengembangan pasar dalam hal membuka beberapa cabang-cabang dibeberapa wilayah di Indonesia agar dapat menjangkau kebutuhan pengguna jasa pembukuan. Pengembangan Produk Kantor Jasa Akuntan Yohanes perlu melakukan pengembangan jasa-jasa seperti jasa persiapan intial public offering, jasa system informasi teknologi dan jasa pendampingan Wajib Pajak di pengadilan pajak.

Ketiga, penetrasi pasar Kantor Jasa Akuntan Yohanes perlu melakukan penempatan jasanya ke pangsa pasar yang paling menarik dalam rangka meningkatkan pelayanannya. Kantor Jasa Akuntan Yohanes perlu berusaha untuk meningkatkan pendapatan dari jasa yang saat ini dipasar lamanya, melalui bauran pemasaran yang lebih agresif.

\section{DAFTAR PUSTAKA}

David, F. R. (2004). Manajemen Strategis: Konsep. Edisi ketujuh. Jakarta: PT Prenhallindo.

David, F. R. (2011). Strategic Management, Buku 1. Edisi 12. Jakarta.

David, F. R. (2009). Manajemen Strategis. Jakarta: Salemba Empat.

Nawawi, Maupa, Ismail. (2019). Aspek knowledge management terhadap kinerja karyawan melalui keunggulan bersaing kantor pusat PT. Bank Sulselbar. Jurnal HJABE, 2(4), 2939.

Peraturan Menteri Keuangan tentang Akuntan Beregister, No. 216/PMK.01/2017 (2017).

Rangkuti, F. (2002). Measuring Customer Satisfaction. Jakarta: Penerbit PT Gramedia Pustaka Utama. 